\title{
Becoming-Animal in the Flesh: Expanding the Ethical Reach of Deleuze and Guattari's Tenth Plateau
}

\author{
LORI BROWN
}

In his article, “...From Wild Technology to Electric Animal,” critical theorist Akira Mizuta Lippit explores the limitations of our ethical engagement with other animals. ${ }^{1} \mathrm{He}$ asserts that our ethical response is restricted by our assumption that identification is required for this kind of exchange. We base our ability to identify with another on shared modes of subjectivity, conceptual language, reason and consciousness. Using these standards, we approach the other animal as an incomplete subject. He writes: "Since the animal possesses no discernible subjectivity, the human subject cannot rediscover itself in the place of this other.... [An] impenetrable screen—language—divides the loci of animal and human being" (120).

Lippit calls on Krafft-Ebing's work on pathological bestiality to support his claim. According to Krafft-Ebing, violent acts committed against other animals are possible because, as Lippit writes, "animals supplant the immediacy of human encounters" (121). Lippit believes this is due to the fact that the animal's gaze "does not terminate the momentum of identification, but rather deflects it into another economy." We may identify with the other animal as a fellow embodied, sentient being. However, because we assume an impassable division separates us, this identification becomes displaced and mutates into a form that does not hold us accountable to the responsibilities that emerge specifically through a shared language and mode of consciousness. 
Underlying this structure is the fact that other animals have no ontology. They "have been excluded from the essential categories that constitute being" (123). Yet, at the same time, animals are "essential supplements" to those categories, because they locate their borders.

In his work, Lippit highlights the primary characteristics we use to cordon ourselves off from other animals: namely subjectivity, conceptual thought and language. Further, he emphasizes the way we use the boundaries we instantiate between ourselves and other animals to define ourselves as ethical subjects and circumscribe the limits of our responsibility. I would add that while we may look beyond the human community when making ethical decisions, we have difficulty viewing other animals as active contributors to this process. We often talk about our ethical partners as mere "moral patients." As a result, we abandon the possibility of a collaborative approach to living that moves beyond the human community.

How do we engage ethically with other animals—not as our patients but as our partners? What are the means through which we can co-create novel ways of being in relationship with one another? I am interested in exploring the resources we have for collaborating or allying with other animals. In this view, the other animal has as much of an impact on us as we have on them. I wish to gather methods that enable us to be cognizant of, surprised by and open to the power that other animals have to alter us. In the process, I intend to counter the assumption that the difference is too great between us and other animals to enable robust forms of ethical interaction. In the pages that follow, I will survey the tools that Gilles Deleuze and Félix Guattari offer us for engaging differently with the animal other in their text, A Thousand Plateaus: Capitalism and Schizophrenia. Specifically, I will work with their concept of becoming as it is developed in their tenth plateau, "1730: Becoming-Intense, Becoming-Animal, Becoming-Imperceptible..." I will argue that becoming offers us a way of thinking about the mechanics of the kind of exchange I 
have in mind. This concept provides us with an alternative to subjectivity and the process of identification that Lippit highlights. Through becoming, we join with the other animal in a zone of proximity that dissolves our identities and the boundaries that we set up between us. This process disturbs and disrupts our usual ontological categories. The resultant zone is a field where novelty and creativity can occur. New ways of relating to one another proliferate here. These creations are the possession of neither entity participating in the becoming; they are created by the shared event of becoming itself. The novel "lines of flight" that are formed in this zone have the power to transform us. We are significantly altered by this exchange with the other animal. In the process, the human being moves out of a position of dominance. She slips out of the position of centrality that enabled her to establish the binary of human-animal to begin with.

Deleuze and Guattari's process of becoming can contribute to our attempts to interact with other animals in ways that allow for our shared ability to thrive. Becoming enables us to see another animal as an active, responsive participant in the exchange. Ultimately, this shared experience has the potential to serve as an alternative to the conceptual language and patterns of thought that we share with other human beings. In the process, it opens us up to ethical engagement with other animals. Yet the majority of becomings-animal we find in Deleuze and Guattari's tenth plateau do not directly address the life of the animal participant. The examples they give of becomings-animal generally take place in the midst of mental illness, in music and other art forms, in tales of wild men, vampires and werewolves. While they speak of becominganimal as a means for challenging and breaking up various human institutions, they do not address institutions that have a negative impact on other animals, such as factory farming. Thus, as Steve Baker writes, "Animals, for Deleuze and Guattari, seem to operate more as a device of 
writing ... than as living beings whose conditions of life were of direct concern to the writers" (95).

For one who desires a process of becoming for the sake of exploring relational and ethical possibilities with other animals, Deleuze and Guattari offer a rather sparse account of these possibilities. The resources are there, but they do not share in this commitment. Thus, I will supplement and enhance their account of becoming with the work of an individual who is invested in this project. Primatologist Barbara Smuts has written a number of articles detailing a becoming that began in a surprising way (as becomings often do) and blossomed into an ongoing, committed investigation into the ways in which we may relate to other animals. ${ }^{2}$ Smuts provides us with an account of becoming in the flesh. She invites us into the very process that perhaps yielded the writings, paintings and music that Deleuze and Guattari describe as the result of their representative becomings. The primary difference in Smuts' approach is her demand for a committed and caring engagement with the animal other. ${ }^{3}$

The transformations that Deleuze and Guattari's becomings facilitate do not necessarily yield positive ethical consequences for the other animal. In order for this to happen, becoming must be accompanied by an interest in the well-being of our partner. It may seem that approaching a becoming with this level of intention may alter Deleuze and Guattari's concept enough to nullify it. However, while they speak about becomings as events that we are swept into, they also speak about becomings that people intentionally take on. Alexis the Trotter, for example, was committed to becoming-horse in a myriad of ways-from whinnying and rearing up to whipping himself with a horseracing switch (305). ${ }^{4}$ If Alexis the Trotter could becomehorse in this deliberate way, surely Smuts and others committed to exploring the relational 
potentials between humans and other animals can participate in this process with a similar level of intention.

\section{Becoming-Animal, Becoming-Molecular, Becoming-Modifiable}

What exactly is becoming-animal? Let us begin with what it is not. According to Deleuze and Guattari, it is not resemblance, identification nor imitation. It is not an act of the imagination, a dream nor a fantasy. Becomings-animal are real. "But which reality is at issue here?" Deleuze and Guattari ask. "For if becoming-animal does not consist in playing animal or imitating an animal, it is clear that the human being does not 'really' become an animal any more than the animal 'really' becomes something else." They assert, "Becoming produces nothing other than itself... What is real is the becoming itself, the block of becoming, not the supposedly fixed terms through which that which becomes passes" (238). The block, the alliance that is formed, is key. Deleuze and Guattari call it a block because it encompasses the zone of proximity that we enter into in our efforts to become the other. It "sweeps up" the human being with the animal other into a relationship. But this is not a linking together of two distinct points. It results in the disappearance of these two discernible points, the freeing from fixed form (238-239).

Deleuze and Guattari refuse to weigh in on the status of the "real" entities here, because to speak of a "real" dog, for example, is to refer to an animal that is "trapped" in its molar form. Molar identities are characterized by Deleuze and Guattari as rigidly fixed, "unifiable, totalizable, organizable." Molecular multiplicities, on the other hand, are "libidinal ... intensive multiplicities ... that constantly construct and dismantle themselves in the course of their communications, as they cross over each other..." (33). 
Becomings are always molecular. To better grasp this claim, it is helpful to have an understanding of Deleuze and Guattari's definition of an individual. First and foremost, an individual is a body. This body is defined as "the sum total of the material elements belonging to it under given relations of movement and rest, speed and slowness..; the sum total of the intensive affects it is capable of at a given power or degree of potential ... Nothing but affects and local movements...." And so there are individualities, but they are not subjects. Instead, they are "relations of movement and rest between molecules or particles, capacities to affect and be affected" (260-261). These individualities or molecular multiplicities are formed out of an ongoing series of different becomings. Consequently, they upset our attempts to classify and organize. Deleuze and Guattari tell us that a wolf, for example, "is not fundamentally a ... certain number of characteristics; it is a wolfing" (239). It and all "elements" within the plane of Nature are actions more so than categories of being. As such, they challenge our attempts to reduce all (a rich field of difference with no one being serving as the point of reference) to one (the world evaluated against the standard of the human being and the resultant fixed binarieshuman/animal, culture/nature).

The becomings that take place between these molecular multiplicities are fueled by desire. Desire to become another animal for Deleuze and Guattari is a longing for proximity and sharing. When they say that a person desires the swarm of the wolf, this is not a matter of her wanting to become "like" a wolf. The desire is actually to enter into a molecular engagement with the other; to be "copresent" with the other in a zone of closeness (272-275). This proximity yields a shared transformation. Our organs are "uprooted" from their "specificity" in order to "become "with"" the organs of the other animal (259). They write: "It is a question of composing a body with the animal, a body without organs, defined by zones of intensity or proximity" 
(274). To become another, you must approximate their patterns of movement, rest and speed, right down to the level of your and their molecular particles. Deleuze and Guattari believe that this process is possible, because the human body has within it "an objective zone of indetermination or uncertainty, 'something shared or indiscernible,' a proximity 'that makes it impossible to say where the boundary between the human and animal lies...." (273). They see this zone as a source of creativity, an inhuman possibility that exists within our bodies that has the potential to emerge.

In spite of the multiple or pack nature of all beings, a human's becoming-animal must be initiated in an alliance with what Deleuze and Guattari call an anomalous individual. It is the animal in the pack that is situated at and helps define the borderline of the pack. The status of this individual is often unknown: are they in the pack, on the border of it, or outside of it entirely? The individual could be the leader of the pack or, like Moby-Dick, an animal that has left the pack and travels alone. Either way, the role of the anomalous individual is to carry "the transformations of becoming or crossings of multiplicities always farther down the line of flight" (243-245). In other words, this individual draws us into a movement away from our molar identity and toward a zone of new ways of being, relating. This zone is one of novelty and possibilities. A line of flight emerges within this zone or block of becoming. This new line runs perpendicular to the molar points of human and other animals. They call this line "created, liberated" (297). In this sense, it is freed from the ways we assign rigid identities to the two terms that are in relation to one another. It allows for something new to emerge, which they believe is also liberatory or freed from the ways in which things have previously taken place between these two "terms" or "points" of the relationship. 


\section{The Ethical Consequences of Becoming}

Deleuze and Guattari claim that a becoming is always a "political affair." Why? Because that which we become is always in a minoritarian position. Ordinarily, the entity occupying the majoritarian position - in this case, the human being - dwells in the site of dominance and "organizes" an oppositional dualism, instantiating itself as the central point of reference. When we become-animal, we shift from this majoritarian position into the location of the other animal. Already at the outset, then, this becoming poses a challenge to a system that enables us to establish a binary grounded in the human domination of the animal (291-292). In the process of becoming, we develop an awareness of the way other animals slip out of the grasp of our classificatory structures and our delineations of their attributes and abilities. We "enable" them to surprise us, and we become curious about what those surprises reveal to us about them, ourselves and the plane on which we exist.

This plane of existence is itself a process of becoming: a field of co-existing, interpenetrating multiplicities. As Claire Colebrook notes, life for Deleuze and Guattari is "an open, creative whole of proliferating connections" ordered neither by language nor logic (5). The human subject is only the "effect of one particular series of experiential connections," one assemblage in the world among many (81). Like any other assemblage, she is no more capable of expressing the world than another. Language and human experience are thus neither epistemically foundational nor particularly normative. Human values in this case simply express the perspective of one form of becoming. Consequently, as Colebrook writes, it becomes necessary to expand our understanding of values as "effects of the flow of life. This means moving beyond morality ... to ethics, where we create and select those powers that expand life as a whole, beyond our limited perspectives" (96). 
In this expanded view, ethical consideration is not tied to the organs or form which an entity owns or inhabits. Whether the body is animal or human is really not the point. Instead, ethics are tied to the limits and capacities of that body. According to Deleuze and Guattari, we must come to know what a body can do, its potential for interacting with other bodies, whether or not that interaction will bring harm to either body and whether there is the potential for exchange or a joining together to form a still stronger body. They give the example, drawn from Freud, of Little Hans watching the assemblage of "draft horse-omnibus-street." The horse is not a representation for Hans, but a list of affects: the horse is powerful enough to carry a heavy load, but it is also "capable of" falling and when it does, it cannot get back up and is whipped to death (257).

Deleuze and Guattari argue that Hans' ethical response to this situation is neither identification with the horse nor sympathy or pity. They illustrate this point further with a description provided by writer Hugo von Hofmannsthal on his observations of a dying rat. They write: "When Hofmannsthal contemplates the death throes of a rat, it is in him that the animal 'bares his teeth at monstrous fate"' (258). They believe that what happens here is a symbiosis, an "unnatural participation." The rat becomes a thought of Hofmannsthal, and Hofmannsthal becomes the rat in the midst of her death throes. "The rat and the man are in no way the same thing, but Being expresses them both in a single meaning in a language that is no longer that of words, in a matter that is no longer that of forms, in an affectability that is no longer that of subjects" (258). Again, this is not an act of the imagination, but "a composition of speeds and affects on the plane of consistency" (258).

The demand that intersubjectivity be required for full ethical engagement is no longer in play here. Instead, the ethical interconnection between Hofmannsthal and the rat is a formless 
circulation of affects. This connection goes much deeper than mimesis or identification. The process of becoming alters both parties right down to the molecular level. Hofmannsthal is physically transformed by his exchange with the rat. It is not language that is enabling this transformation (although written expression is one of its results). The meaning that Hofmannsthal and the rat share is of a different order. It is composed not of symbols but of movement, speed and affect. In the process, the boundary that existed between man and rat is rendered indiscernible by the block of their mutual becoming. According to Deleuze and Guattari, this unnatural participation leads the writer to experience "the incredible feeling of an unknown Nature-affect." This affect is not a "personal feeling" so much as it is the manifestation of the pack's ability to "[throw] the self into upheaval" (240). The author "reels" from his witnessing and expressing of another animal's death. He is overwhelmed before it. He is further drawn into a symbiotic alliance with the other animal. He feels responsible before the other animal.

Deleuze and Guattari do not tell us in their tenth plateau what it means to be responsible before the other. In the process of becoming, of aligning movement with movement, do we become aware of what the other animal needs in order to thrive? Can we attend to what takes place in this becoming? In order to answer these questions, I turn now to Barbara Smuts.

\section{Becoming-Animal in the Flesh}

In her article, "Encounters with Animal Minds," Smuts develops a framework for the ways in which humans can relate to other animals. She comes to this exploration with 25 years of experience as a primatologist conducting field studies in Kenya and Tanzania. She draws primarily from a 2-year period of time when she traveled for 12 hours a day, 7 days a week, with 
a troop of 135 baboons. She also refers often to her relationship with Safi, her dog companion, as an example of how her experience with the baboons altered her interactions with other animals (294).

It is not readily apparent from her writing that Smuts participates in anything like a becoming. She is firmly committed to the concepts of subjectivity and personhood. However, while Smuts uses these concepts, these phenomena derive from the connections between us. She writes: "Thus while we normally think of personhood as an essential quality that we can 'discover' or 'fail to find' in another, in the view espoused here personhood connotes a way of being in relation to others" (Smuts, "Reflections" 118). Personhood is a capacity more than a characteristic for Smuts; it is an ability to participate in relationships (118). She maintains that we must sense a "presence" in the other party in order to establish mutuality. This presence is "something we feel more than something we know." Smuts asserts that this presence, this sense that there is "someone home" who is able to co-create and experience a shared reality, is a capability that exists for her in humans and other animals. She insists, moreover, that this shared reality can only be approached through a "creative and caring" engagement with the other (Smuts, "Encounters" 308). ${ }^{5}$

In addition to her emphasis on subjectivity and personhood, Smuts maintains a certain reliance on the language of individuality. Rather than see this as a form of molar identity or subjectivity, however, it is possible to view her individual as akin to Deleuze and Guattari's anomalous individual. Her companion dog, Safi, seems to play this role. At several points in her work, she states that Safi is more attuned and aware than perhaps many other animals, including humans. She is keenly open to engaging in the kind of exchanges that Smuts finds arresting and surprising. She engages with Smuts in a kind of communion that is usually practiced within 
species. She stands out from the "pack" in the myriad of ways in which she acknowledges Smuts. She enables crossings-over between previously well-defined categories of beings. Safi, in other words, is just the kind of animal who can participate in a becoming. Smuts believes this may have something to do with Safi's "genetic endowments" (she is a mix of German Shepard and Belgian sheepdog), but ascribes it as well to the fact that Safi has lived her life with someone who has seen beyond what Deleuze and Guattari would call her molar being (Smuts, "Encounters" 306). She attributes her ability to engage in a relationship of mutuality with Safi to her post-baboon capacity to "surrender expectations about who [Safi] was or what she could or could not do based on her species identity" (303).

Like Deleuze and Guattari, Smuts is highly critical of molar being. She asserts that most pet-lovers are limited in their relationships with their animal companions by their "narrow set of assumptions about what their animals are capable of, and what sort of relationship it is possible to have with them" (Smuts, "Reflections" 115, 120). Smuts maintains that the limits we imagine animals have for participating in meaningful relations with us are less a reflection of their inadequacies and more a matter of our restricted viewpoint.

\section{A Desire for Proximity}

As with Deleuze and Guattari, Smuts asserts becoming is fueled by a desire for proximity. She regards this desire as a two-way process. For example, in her work as a primatologist, she was encouraged by her colleagues to keep her distance from the baboons. However, one day a baboon approached her. She writes: "When she was about two feet away (an undeniable overlap of personal space), she grunted softly several times without looking up. I turned my head to see whom she was grunting at, and, spotting no other baboons within 15 
yards, realized that she was talking to me" (Smuts, "Encounters" 296-297). In this sense, the baboon — an anomalous individual standing out from the pack—invited Smuts into a proximal relationship. After observing the various meanings proximity held for the baboons, Smuts came to realize that ignoring a baboon's closeness to her was in no way a neutral act. Consequently, she made the decision to begin gesturing to the baboons, she tells us, "in ways I picked up from them" to communicate that she was not a threat (297). She talks about a shift in their interactions when the baboons began not simply to retreat from her but to give her dirty looks. She believes that this was a transitional moment when they began to view her as "a social being like themselves, subject to the demands and rewards of relationship" (295). Smuts responded by acknowledging an ethical obligation to read and respect their demands to be left alone, as well as their invitations for interaction.

Rosi Braidotti claims that a desire to change is essential to becoming-animal in a way committed to letting go of standard power relations. Braidotti sees becoming as a recognition that old ways of doing things-both social and symbolic - are no longer satisfactory. She believes Deleuze's notion of becoming is a "theory of desire: the only possible way to undertake this process is to actually be attracted to change, to want it...in the flesh" (70). She sees this desire to change as a political act, because it enables us and others to break out of socially sanctioned modes of being. Further, she maintains that a being is only able to transition by giving up its place in the "web of power relations on which it used to rest" (70). Smuts' willingness to alter her stance on neutrality when she saw that it carried a certain meaning for the baboons is an example of this kind of desire. Her readiness to be guided by other animals into different ways of interacting began a transition that led to her ability to relate differently to them. 
Smuts believes that prolonged proximity between members of different species results in a creation of "shared conventions that help to regulate interspecies encounters" (Smuts, "Encounters" 302). It is questionable whether Deleuze and Guattari would agree with a language of convention and regulation. I hold on to this phrasing here, however, to highlight the way in which a shared becoming allows for the development of new forms of interaction between species. For Smuts, it is often centered on the ability to match bodily comportment, gesture and rhythm. She writes about her experience with the baboons:

I.., in the process of gaining their trust, changed almost everything about me, including the way I walked and sat, the way I held my body, and the way I used my eyes and voice. I was learning a whole new way of being in the world - the way of the baboon. I was not literally moving like a baboon-my very different morphology prevented that - but rather I was responding to the cues that baboons use to indicate their emotions, motivations and intentions to one another, and I was gradually learning to send such signals back to them. (Smuts, "Encounters" 295)

The very possibility for a relationship and ethical responsibility begins for Smuts when our movements are aligned. We often see this in her descriptions of her relationship with Safi. She notes that her ethical engagement with Safi depends on her ability to take note of the rhythm of her movements and respond in kind. She writes that Safi usually employs nuanced, subtle gestures when communicating with her. For example, she describes Safi as gently nosing the back of her knee when Smuts has become distracted from their interaction by another person. She writes: "Through encounters like these, I have developed a deep appreciation for the subtlety and gentleness of [Safi's] communication, and I have tried to respond in kind" (Smuts, "Reflections" 115-116). Smuts uses Safi's treatment of her as a cue for all of her interactions with her. She matches Safi's gestures, in a sense, with a similar tonal quality. Thus, her actions toward Safi are impacted by the quality of Safi's engagement with her. Together they take part in a gestural call and response that is altered every step of the way. 
Smuts also speaks about their rituals of shared, embodied, complementary movements that seem to have no source. She notes: "I can't explain how any of them came into being. Certainly, I did not invent them, and I don't think [Safi] did either. Rather, they developed spontaneously in the intersubjective space we inhabit together" (Smuts, "Encounters" 304). She maintains that these shared rituals "simultaneously [reveal] a mutual past and an ongoing commitment to a common future in which the circle of shared experience and fellow feeling grows ever larger" (304). Smuts likens these shared rituals to the ways in which other animals co-exist in packs: "This is the way of female baboons living their lives together in the same troop. This is the way of the wolves whose survival depends on enduring commitments to other pack members" (304). For Deleuze and Guattari, the pack itself is a rich ground for becomings; it compels its members to enter into involutions, alliances (241). Smuts tells us that we, too, can be drawn into similar alliances with other animals - alliances that ensure our mutual flourishing.

\section{The Transformative Power of Interpenetration}

For Deleuze and Guattari, becoming-animal is characterized by interpenetration with the other. Smuts not only describes a similar merging but also incorporates it into her view of mutuality. We see, for example, Smuts describe her transformation among the baboons as a kind of becoming-pack animal. She tells us that during her fieldwork, she felt like she was becoming a baboon. She writes: "Increasingly, my subjective consciousness seemed to merge with the groupmind of the baboons. Although 'I' was still present, much of my experience overlapped with this larger feeling entity. Increasingly, the troop felt like 'us' rather than them" (Smuts, "Encounters" 299). Smuts experienced this transition in a deeply embodied way. She began to identify the baboon's predators and their prey as her own and became attuned to the "mood of the troop" 
when she approached them. She writes: "I could usually tell whether we were going to travel a short or long distance that day. Often, I anticipated exactly where we would go, without knowing how I did it" (300). Smuts was "infected" by the pack.

Interpenetration figures in the deepest stage of Smuts' levels of human-other animal relating. At the basic level, both human being and other animal are categorized and viewed in their molar identity (e.g., potential predator or research subject). Over time, they begin to distinguish this individual from the species and see that she may respond in ways different from the category of "human being" or "baboon." Then they begin to view one another as partners in social interactions with the ability to communicate and negotiate the terms of their relationship. The final two levels are characterized by a mutuality, whereby the participants transcend "the particulars of either animals' individual or species-specific repertoire" and co-create a shared vocabulary of movement (Smuts, "Encounters" 307). Smuts believes that the final level is one of complete interpenetration: "separation dissolves (at least temporarily)" (308).

Becomings may reveal to us the ways in which others alter us in a deeply constitutive manner. If we attend to the participation of the other in becoming, we come to recognize the power or capacity they have to shape us. It awakens us to the possibility for joint action and creation. It is an opening up to the animal that enables us to see them as partners. For many of us, this is a role that we do not often grant to or acknowledge in other animals. Smuts has developed an ability and a willingness to be altered by the other animals in her life. In the process, she has acknowledged their relational, compositional power. Deleuze and Guattari describe love as a process whereby you extract a person from the mass in which they participate in a kind of molar engagement, discover the multiplicities within them and then interpenetrate your own multiplicities with those of the loved one (35). In her commitment to observing the rhythms and 
modes of living that the animals in her life express and her willingness to be shaped by the differences that she finds, I believe Smuts exemplifies this kind of love.

\section{Conclusion}

In their notion of becoming-animal, Deleuze and Guattari inadvertently provide us with tools for engaging ethically with others who do not share our forms of language and thought. Smuts' effort to create a new framework for human-other animal relating helps bring these tools to bear more directly on these relationships. Her model demands a questioning of our rigid, molar understanding of the capacities of other animals; a relaxing of the boundary between species; an emphasis on the matching of another's movements as a valid form of communication and a foundation for ethics; and an interpenetration that yields a shared, co-created field of meaning and a concomitant ethical engagement.

Deleuze and Guattari comment on Virginia Woolf's response when questioned about women's writing: “[S]he was appalled at the idea of writing 'as a woman.' Rather, writing should produce a becoming-woman as atoms of womanhood capable of crossing and impregnating an entire social field, and of contaminating men, of sweeping them up in that becoming" (276). When someone like Smuts becomes-animal, perhaps she contaminates the human majoritarian and sweeps them up in these becomings in a similar way. This is a transformative act that can significantly impact the way majority human relates to minority animal. In this way, Smuts brings the socially transformative and liberatory potential of becoming to bear on our relationships with other animals. As a consequence, the boundaries that circumscribe who is worthy of our ethical consideration are relaxed and the net of our ethical engagement is significantly widened. 


\section{Notes}

${ }^{1}$ I am grateful to Ted Toadvine, University of Oregon, for his comments and mentorship on this article; Hasana Sharp of McGill University for her commentary on an earlier version of this paper delivered at the EPTC 2007 Conference panel entitled "Recent Continental Perspectives on Animals;" the panel organizers, Chloë Taylor of McGill University and Lisa Guenther of Vanderbilt University; and the panel participants for their suggestions.

2 The concept of becoming is admittedly complex. It is likely that Deleuze and Guattari were drawing from different resources than Smuts when developing their concept of human-other animal interaction. Further clarification of the concept of becoming-animal would be needed to explore how far a correspondence can be drawn between the work of Smuts and Deleuze and Guattari. My thanks to Ted Toadvine for this observation.

3 For Deleuze and Guattari, a becoming neither requires this kind of commitment nor is particularly caring. They tell us that the "anomalous" animal other with whom we participate in a becoming "is neither an individual nor a species; it has only affects, it has neither familial or subjectified feelings ... Human tenderness is as foreign to it as human classifications" (244-245).

${ }^{4}$ Deleuze and Guattari claim Alexis reached the deepest zone of proximity to a horse, however, when he abandoned these mimetic practices and adopted the tempo of a horse while playing the harmonica (305).

${ }^{5}$ As noted earlier, this stipulation distinguishes Smuts from Deleuze and Guattari.

\section{Works Cited}

Baker, Steve. "What Does Becoming-Animal Look Like?" Representing Animals. Ed. Nigel Rothfels. Bloomington: Indiana University Press, 2002. 67-98.

Braidotti, Rosi. "Meta(L)Morphoses." Theory, Culture \& Society 14.2 (1997): 67-80.

Colebrook, Claire. Gilles Deleuze. London \& New York: Routledge, 2002.

Deleuze, Gilles, and Félix Guattari. A Thousand Plateaus: Capitalism and Schizophrenia. Trans. Brian Massumi. Minneapolis \& London: University of Minnesota Press, 1987.

Lippit, Akira Mizuta. "...From Wild Technology to Electric Animal." Representing Animals. Ed. Nigel Rothfels. Bloomington: Indiana University Press, 2002. 119-136. 
Smuts, Barbara. "Encounters with Animal Minds." Journal of Consciousness Studies 8.5-7 (2001): 293-309.

—. "Reflections." The Lives of Animals. Ed. Amy Gutmann. Princeton, NJ: Princeton University Press, 1999. 107-120. 